\title{
Research on Vegetable Cultivation Suitability of Time and Space Optimization
}

\author{
Xinjiang LI \\ Jilin Agricultural Science and Technology University, Jilin, China
}

\begin{abstract}
This paper takes lettuce, radish and tomato as research material to determine soil suitability of vegetable growing in different regions through establishing model for evaluation factors of vegetable growth suitability. It provides both fundamental theoretical guidance for annual vegetable variety production from the point of view of soil nutrients, and scientific proof for appropriate selection and distribution of vegetable production bases. However, due to the lack of data of other nutrition element contents in the soil, this paper evaluates calcium, magnesium, soil moisture, and planting fitness of the land. We can make further evaluation and comparison on other elements that are not involved in this paper in future research through research methodology in this paper.
\end{abstract}

KEYWORD: Vegetable Cultivation, Suitability, Space Optimization

\section{THE PRESENT DEVELOPMENT SITUATION OF ORGANIC VEGETABLE}

As a part of organic agriculture, organic vegetable is a sustainable agriculture system which has the strictest requirement for production. It mainly relies on local available resources, improve natural biological cycle, follow the laws of nature and the ecological system, must be carried out in accordance with the organic production method, and strictly complies with technical standards for organic food production. It adopts sustainable agricultural technologies to maintain a stable production, but not uses pesticides, chemical fertilizers, growth regulators and other chemicals and genetic engineering technology.

Organic vegetable has received importance early and made great progress in many countries. The production area of organic vegetable in America ranks first in the world, and organic vegetable in Italy taking up total planting area becomes one of the main organic products. In addition, the production scale of organic vegetable in Mexico, Thailand, Netherlands and other countries has been on the top of the world. On the technical side, many countries have full control for organic vegetable production, and set up organic vegetable production, transportation, storage, processing and marketing systems.

\section{THE DETERMINATION OF INPUT OF EVALUATION MODEL}

Vegetable's responses to climate are heat and water. Heat affects the growth of vegetable through temperature and light. Physical activities of the growth of vegetable must be under the conditions of a certain temperature, light and moisture. According to needs and responses to temperature, light, and moisture of the growth of vegetable, this research takes temperature, the percentage of sunshine and rainfall factors as evaluation factors of suitability of vegetable growth in combination with the selection of index and availability of data in predecessors' research on the crop climate suitability,

Climate suitability evaluation of crop growth is a concluding evaluation in terms of climatic suitability of certain crop grown in specific area. Through the establishment of vegetable growing season (excluding nursery) climatic suitability for membership functions of vegetable growth, combining actual conditions of climate month by month with climatic indexes suitable for vegetables to make a comparison and analysis, and to obtain the membership function of climatic elements month by month as an index of climate suitability evaluation of vegetable growth. Then, making comprehensive analysis of the membership function of monthly temperature, light, and water. Eventually, obtaining integrated monthly climate suitability index to make comprehensive evaluation of $h$. 
The determination of membership function in temperature. In the past researches, many scholars hold different opinions on specific forms of membership function in climate suitability on vegetable growth. The function determined by $\mathrm{Ma}$ Shuqing has been widely used. The requirement and response to temperature of vegetable growth is the same as food crops, suitability strengthening first and then weakening following the rise of temperature within the maximum and minimum temperature, which forms unsymmetrical parabolic functions. Therefore, this research quotes $\mathrm{Ma}$ Shuqing's membership function in temperature suitability directly in order to quantitatively analyze the extent of the area of each month to meet the climatic conditions on vegetable growth. Formula (1) is as follow.

$$
\begin{aligned}
& S(T)=\left\{\begin{array} { l } 
{ \frac { ( T - T _ { 1 } ) ( T _ { 2 } - T ) ^ { B } } { ( T _ { 0 } - T _ { 1 } ) ( T _ { 2 } - T _ { 0 } ) ^ { B } } } \\
{ 1 }
\end{array} T _ { 1 } \left\langleT \left\langleT_{2}\right.\right.\right. \\
& B=\left(T_{2}-T_{0}\right) /\left(T_{0}-T_{1}\right)
\end{aligned}
$$

In the formula, $T$ stands for the actual temperature of each month; $T_{1}, T_{2}$ and $T_{0}$ are respectively minimum temperature, maximum temperature and optimum temperature; $S(T)$ stands for temperature suitability value determined by actual temperature of each month, $T_{1}, T_{2}$ and $T_{0}$. When $S(T)$ evaluates to zero, it means it is not appropriate; when $S(T)$ evaluates to one, it means it is very appropriate.

(2)The determination of membership function in light. According to the response to light of vegetable, from the point of view of the percentage of sunshine, this paper uses the normal distribution of fuzzy subset in fuzzy mathematics to establish membership function. Formula (2) ${ }^{[87]}$ is as follow.

$$
S(S)= \begin{cases}\mathrm{e}^{-\left(\frac{h-h_{b}}{b_{r}}\right)^{2}} & h\left\langle h_{0}\right. \\ 1 & h \geq h_{0}\end{cases}
$$

Resource index stands for crop growth period of climate resources in appropriate conditions. The bigger it is, the higher the extent of average climatic resources suitability in the crop growth period it is. In most studies in the past, it only means crop growth period of climate resources in appropriate conditions. According to the basic requirements to the parameters of the model, this study has collected data for many years, aiming at a comprehensive overview of vegetable growth for every month, and receiving monthly resource index, so there is no need to consider vegetable in all growth stages. Therefore, the author modifies the model to regain resources index formula.

\section{RESULTS AND ANALYSIS}

Temperature has a distinct effect on the growth of vegetable. Except for the high temperature season in January, that is from the middle of a month to late month of next year, membership function value of temperature is above the average. It shows that the temperature in this period is suitable for the growth of spinach in open field. But in particular, the most suitable period of temperature of spinach growing in open field is mainly divided into two phases, which are respectively from the end of a month to the end of a month, and the late month to the beginning of a month. And the membership function value of temperature is above the average. Center on this, it can be expanded from late month to the end of a month, the end of a month to the end of a month and the beginning of a month to the middle of a month, whose membership function value is between the average. But if the spinach is covered by the small arch shed or against the sun near the ground, it can promote the green up ahead of time and the growth of spinach. The period from late May to early September, due to the high temperature, spinach growth temperature is low, which is not suitable for growth of spinach. But in order to increase vegetable varieties, it is of certain production significance.

Under the conditions of open field cultivation, regardless of artificial irrigation, rainfall is crucial to vegetable growth. Based on the demand for moisture of spinach, in combination with precipitation in Shanghai Pudong in each month, moisture suitability of spinach growth is from month to month of next year. This month is divided into two period, which are centered on late month to early month and the end of a month to early month. Membership function value of moisture of spinach in the period from late month to early month is above the average, up to the maximum.

The minimum and maximum value of spinach are respectively 0.5644 and 0.9375 in the period from late month to early month. Center on former period, moisture suitability period of spinach growth can be expanded from early September to late December. Center on latter period, it can be expanded from late February to June, whose membership function value of moisture is between 0.70 and 0.50 . Only the moisture condition in January and February is not suitable for spinach grow, which needs to drain or keep of rain for spinach based on specific precipitation.

Establishing model for evaluation factors of vegetable growth suitability is equivalent to establish mathematics formula of the relationship between nutrition factors and time-effect curve of growth of crop. According to crop growth, it can be known that at the current level, the membership functions of the content of three elements, N,P and K in cultivated soils in China shows the curve of s-shaped, and in 
certain range there is a positive correlation between evaluation factors and growth of vegetable. Because this study is to do qualitative evaluation for suitability, when the content of certain nutrient in plough layer is lower than that of vegetable demands, degree of membership is set as zero. Membership function is established as follow in combination with half-rise and normal distribution in fuzzy mathematics

Weight refers to the impact or contribution rate of evaluation of factors on the object. Different functions and roles of each index in soil fertility have different influence on fertility. Weihgt, the evaluation factor of soil suitability for vegetable is determined by Analytic Hierarchy Process $(\mathrm{AHP})^{[97-98]}$. AHP makes complex decision-making system hierarchical through establishing hierarchy model, constructing matrix of pair-comparison, calculating weights and doing consistency check, and calculating the combined weight and doing mix consistency check to determine the weight in soil factors. There are only three factors that determine weight in this paper and one hierarchy, so it is done through constructing matrix of pair-comparison and calculating weights and doing consistency check.

Comparing and analyzing soil suitability of lettuce planted in towns in Pudong, it can be found that the highest degree of membership of available nitrogen in soil is in Xinchang Town, showing that content of available nitrogen in plough layer in Xinchang Town is more suitable for the growth of lettuce demanding for it. The second one is horticultural field, showing that available nitrogen in gardening soil containing more available nitrogen is more suitable for growth of lettuce after years of vegetable cultivation. The rest are Huinan Town and Datuan Town. The lowest degree of membership is in Luchaogang Town, whose content of available nitrogen cannot meet the needs of lettuce on nitrogen, so it needs to fertilize some nitrogen fertilizers in the soil .

The highest degree of membership of phosphorus in soil is in horticultural field, whose value is far higher than that of other towns. Probably available phosphorus in fertilizer makes complement for soil, so the content of available phosphorus in soil in horticultural field is more suitable for the growth of lettuce. The rest respectively are Huinan Town, Xinchang Town and Datuan Town. The highest degree of membership of phosphorus is in Luchaogang Town, so it needs fertilizer with a low phosphorus content when planting lettuce.

The highest degree of membership of potassium in soil is in Luchaogang Town, and the second one is in horticultural field. The content of available potassium in these two places more meets the needs of lettuce on potassium. The rest are in Huinan Town and Datuan Town. The lowest degree of membership of potassium in soil is in Xinchang Town, so it needs potassium fertilizer when planting lettuce.

Comparing and analyzing soil suitability of radish planted in towns in Pudong, it can be found that the highest degree of membership of available nitrogen in soil is in Xinchang Town, showing that content of available nitrogen in soil in Xinchang Town is more suitable for the growth of radish demanding for available nitrogen compared with other towns. The second one is horticultural field, showing that available nitrogen in gardening soil is more suitable for growth of radish demanding for available nitrogen than in other areas after years of vegetable cultivation. The rest are Huinan Town and Datuan Town. The content of available nitrogen in plough layer is lower than that of radish absorbs from the soil each year. Comparatively speaking, the content of available nitrogen in this town cannot meet the needs of radish on nitrogen, so it needs some nitrogen fertilizers in the soil .

The content of available phosphorus in plough layer in Luchaogang Town, Xinchang Town and Datuan Town is lower than that of radish absorbs from the soil each year, so their membership value are average.The highest degree of membership of available phosphorus in soil is in horticultural field, far higher than that of Huinan Town, showing that the average value of available phosphorus in soil in horticultural field is more close to the demand of radish on it. It needs phosphorus fertilizer if planting radish in Huinan Town.

The highest degree of membership of available potassium in soil is in Luchaogang Town, showing that the content of available potassium in soil in Luchaogang Town is more close to the demand of radish on it. The second one is in horticultural field, showing that fertilization on soil through many years helps to accumulate available potassium. The rest respectively are Huinan Town and Datuan Town. The degree of membership of available potassium in soil in Xinchang Town is relatively low, so it needs potassium fertilizer if planting radish.

Comparing and analyzing factors of soil suitability of tomato planted in towns in Pudong, it canbe found that the highest degree of membership of available nitrogen in soil is in Xinchang Town, showing that content of available nitrogen in soil in Xinchang Town is more suitable for the growth of tomato demanding for the content of available nitrogen. The rest are in horticultural field, Huinan Town and Datuan Town. The content of available nitrogen in soilr in Luchaogang Town is lower than the content of available potassium that tomato absorbs from the soil.

The highest degree of membership of phosphorus in soil is in horticultural field, whose value is far higher than that of other towns, showing that the content of available phosphorus in soil in horticultural field is more suitable for the growth of lettuce. Probably available phosphorus in fertilizer 
makes complement for soil. The rest respectively are Luchaogang Town, Xinchang Town and Datuan Town. The lowest degree of membership of phosphorus is in Huinan Town, so it needs fertilizer with ahigh phosphorus content when planting tomatoes.

Because tomatoes absorb large amounts of available potassium in soils, far higher than the available potassium in soil, available potassium contents in soil in each town is average. So it needs potassium fertilizer or selects tomatoes demanding for few potassium when planting tomatoes.

Analysis of suitability of various vegetable is planting in $\mathrm{Pu}$ Dong from 3 comprehensive element of soil can be found that comprehensive suitability of garden is bigger than that of in Pudong in terms of various vegetable. The vegetable and fruit planted in garden may require constant addition of fertile concluding various element of nutrition, which makes the content of various of element of nutrition much higher. Maybe agriculture in these two towns is better than that of others. As we all know, planting crops or another plants all the time can accumulate the nutrition in the soil. In terms of comprehensive suitability, Datuan Town and Luchaogang Town are at the bottom, especially the comprehensive suitability of Luchaogang Town is far lower than others. Maybe the underdevelopment of agriculture or other activities lead to the lack of nutrition in soil.

\section{CONCLUSION}

It can reach the following conclusions by setting up model to analyze soil suitability of three vegetable. The soil of garden is more suitable for growth of various vegetable, which indicate cultivation and farming is good for accumulating various nutrition. Various element of nutrition of soil in each town is less coordinated .In order to avoid influencing sustainable utilization of soil and vegetable because of the low or high element, we should fertilize according to the characteristics of soil and vegetable. On account of comprehensive analysis, Luchaogang Town is most unsuitable for growth of vegetable, so we should take measure to fertilize the soil to assure the soil can accumulate enough nutrition when conducting agriculture production.

\section{REFERENCES}

[1] Xie Zhenhua, Wang Yuqing. China's Encyclopedia of Environment and Science. Beijing: China's Encyclopedia Press, 2002, 69 72.

[2] Tang Qizhan. The Development and Enlightenment of Organic Agriculture in the United States. Guangxi Agricultural Science, 2004, 35(6):517 520.

[3] Xing Ji, Luo Yuwei. Current Development Situation and Enlightenment of Organic Vegetables in Foreign Countries.China Vegetables, 2009, (15):1 5.

[4] Parry M. The Potential Effect of Climate Changes on Agriculture and Land Use. Advance in Ecological Research, 1992. (22):63 69. 